Eur. J. Clin. Chem. Clin. Biochem.

Vol. 32, 1994, pp. 91-95

(c) 1994 Walter de Gruyter \& Co.

Berlin · New York

\title{
Evaluation of an Immunoradiometric Assay for Bone Alkaline Phosphatase Mass Concentration in Human Sera
}

\author{
By W. Withold and W. Rick \\ Institut für Klinische Chemie und Laboratoriumsdiagnostik, Medizinische Einrichtungen der \\ Heinrich-Heine-Universität Düsseldorf, Germany
}

(Received July 12/November 23, 1993)

Summary: The performance characteristics of an immunoradiometric assay for bone alkaline phosphatase mass concentration in human sera are reported.

Within-run imprecision $(\mathrm{n}=20)$ was $12.1 \%(\overline{\mathrm{x}}=7.8 \mu \mathrm{g} / \mathrm{l})$ and $3.6 \%(\overline{\mathrm{x}}=22.8 \mu \mathrm{g} / \mathrm{l})$, between-day imprecision $(\mathrm{n}=8)$ was $10.1 \%(\overline{\mathrm{x}}=20.3 \mu \mathrm{g} / \mathrm{l})$ and $2.8 \%(\overline{\mathrm{x}}=84.3 \mu \mathrm{g} / \mathrm{l})$. There was a linear relationship between the concentrations of the standards employed and the counts per minute up to $120 \mu \mathrm{g} / \mathrm{l}$. The detection limit was $0.3 \mu \mathrm{g} / \mathrm{l}$.

In 102 apparently healthy persons (51 males and 51 females; range of age: 18-56 years) the following reference intervals were established: $3.8-21.3 \mu \mathrm{g} / 1$ (males) and 3.4-15.0 $\mu \mathrm{g} / 1$ (females).

We compared the values obtained using the immunoassay with those obtained by precipitating of bone alkaline phosphatase with wheat-germ lectin (alkaline phosphatase activity concentration was determined at $+25^{\circ} \mathrm{C}$ by the optimized standard method according to the Recommendations of the German Society for Clinical Chemistry). For the reference individuals the relationship between the results of the two methods is given by the following regression equation: Bone alkaline phosphatase activity concentration $[\mathrm{U} / \mathrm{l}]=14.81+3.28 \times$ bone alkaline phosphatase mass concentration $[\mu \mathrm{g} / 1](\mathrm{r}=+0.783)$. In 89 sera from 32 patients before and after renal transplantation (range of bone alkaline phosphatase mass concentration: $2-39 \mu \mathrm{g} / \mathrm{l}$ ) comparison between the two methods yielded a linear correlation coefficient of $r=+0.886$.

Of 20 sera taken from patients suffering from various hepatobiliary diseases (range of total alkaline phosphatase activity concentration: $217-3270 \mathrm{U} / 1) 18(90 \%)$ showed a bone alkaline phosphatase mass concentration above the upper reference limit (range of bone alkaline phosphatase mass concentration: $16-206 \mu \mathrm{g} / \mathrm{l}$ ). This is probably due to a cross-reactivity of the antibodies employed for the immunoassay of bone alkaline phosphatase with liver alkaline phosphatase in plasma. It is concluded that an increased release of liver alkaline phosphatase into serum leads to falsely high values for bone alkaline phosphatase mass concentration, severely limiting the diagnostic validity of the test in such cases.

\section{Introduction}

Human alkaline phosphatases (orthophosphoric monoester phosphohydrolase [alkaline optimum], EC 3.1.3.1) are glycoproteins which can be divided into at least four isoenzyme groups: intestinal, placental, placental-like and hepatic/renal/skeletal. The alkaline phosphatases of bone and liver are coded by a single gene but differ in their degree of glycosylation (for review see 1.c. (1)).
Several methods have been recommended for differentiating between liver and bone alkaline phosphatases, based on the following principles:

(a) Separation of bone and liver isoforms by electrophoresis (2)

(b) Precipitation of bone alkaline phosphatase with wheat-germ lectin, which leaves non-bone alkaline phosphatases in the supernate (3). 
Here we report on the evaluation of an immunoradiometric method for determination of bone alkaline phosphatase mass concentration in human sera. The method employs two monoclonal antibodies, which react with different epitopes of the bone alkaline phosphatase molecule.

\section{Materials and Methods \\ Reference individuals and patients}

Sera were obtained from

(a) 102 apparently healthy persons (51 males and 51 females, respectively), age range 20-55 years (median: 30 years) for males, and 18-56 years (median: 29 years) for females.

(b) 32 patients receiving renal transplants (10 sera before and 79 sera 1 week to 6 months after transplantation).

(c) 20 patients with various hepatobiliary diseases.

All specimens were taken between 8 and 9 a. $\mathrm{m}$. Sera were separated from the blood clot within $4 \mathrm{~h}$ after specimen collection and stored at $-20^{\circ} \mathrm{C}$ for a period of up to 2 months.

Determination of bone alkaline phosphatase mass concentration in serum

Bone alkaline phosphatase mass concentration was determined by an immunoradiometric assay (Tandem ${ }^{\circledR}-\mathrm{R}$ Ostase ${ }^{\mathrm{TM}}$; Hybritech Inc., San Diego, CA [U. S. A.]; No. 3040 BE; lot No. 35077 08G): $100 \mu \mathrm{l}$ of serum were mixed with a plastic sphere coated with antibody and $100 \mu \mathrm{l}$ of ${ }^{125} \mathrm{I}$-labelled second antibody. The reaction mixture was incubated for $17-21 \mathrm{~h}$ at temperatures not above $+8^{\circ} \mathrm{C}$. After three washing steps, radioactivity bound to the spheres was measured with a scintillation counter. The standards used had the following concentrations: $0,15,30,45,60$ and 120 $\mu \mathrm{g} / \mathrm{l}$, respectively. A calibration curve was constructed by linear interpolation between the measuring points. There was a linear relationship between the concentrations of the standards employed and the counts per minute up to $120 \mu \mathrm{g} / \mathrm{l}$.

Determination of bone alkaline phosphatase activity concentration in serum

Bone alkaline phosphatase activity concentration was determined according to Rosalki \& Ying Foo (3) by employing Iso-ALP (Boehringer Mannheim GmbH, Mannheim, Germany; No. 1065769; lot No. 641713): $100 \mu \mathrm{l}$ of serum were mixed with $100 \mu \mathrm{l}$ of a solution containing wheat-germ lectin $(\geq 2 \mathrm{~g} / \mathrm{l})$ for precipitation of bone alkaline phosphatase and Triton X-100 (20 g/l) to prevent coprecipitation of biliary alkaline phosphatase. After incubation for 30 $\mathrm{min}$ at room temperature the mixture was centrifuged at $2500 \mathrm{~g}$ for $10 \mathrm{~min}$. The activity of total alkaline phosphatase in serum and of alkaline phosphatase in the supernate was measured at $+25^{\circ} \mathrm{C}$ by the optimized standard method according to the Recommendations of the German Society for Clinical Chemistry (4) using the fully mechanized analyser Hitachi/BM 704 (Boehringer Mannheim $\mathrm{GmbH}$, Mannheim, Germany). Bone alkaline phosphatase activity concentration was calculated with the aid of the following equation which takes into account dilution of serum by the precipitating reagent as well as an average of $10 \%$ residual activity of bone alkaline phosphatase in the supernate and an average of $5 \%$ of nonbone alkaline phosphatase in the precipitate (5):

Bone alkaline phosphatase activity concentration (in serum) [U/l] $=1.118 \times$ total alkaline phosphatase activity concentration (in serum) $[U / 1]-2.35 \times$ alkaline phosphatase activity concentration (in the supernate) [U/1].

\section{Determination of $L-\gamma$-glutamyl transferase in serum}

$L$ - $\gamma$-glutamyl transferase (EC 2.3.2.2) activity concentration was determined according to Szasz (6) using the fully mechanized analyser Hitachi/BM 737 (Boehringer Mannheim GmbH, Mannheim, Germany) (reference range: 6-28 U/l [males] and 4-18 U/1 [females]).

\section{Statistical analysis}

The statistical methods employed include the U-test according to Wilcoxon, Mann \& Whitney (two-tailed), linear correlation coefficients and linear regression equations (7).

\section{Results}

\section{Imprecision}

Two pooled human sera were analysed 20 times for determination of bone alkaline phosphatase mass concentration and activity concentration, respectively, in order to assess within-run imprecision (tab. 1). The results of between-day imprecision are shown in table 2.

\section{Assay limit of detection}

Twenty replicate analyses of the zero standard were made within a single run, and the assay limit of detection, defined as the concentration corresponding to the $95 \%$ confidence interval of counts, was found to be 0.3 $\mu \mathrm{g} / \mathrm{l}$.

\section{Linearity and dilution}

Linearity of dilution was investigated using 2 human serum samples containing 22.6 and $81.4 \mu \mathrm{g} / \mathrm{l}$ bone alka-
Tab. 1 Comparison of the immunoradiometric determination of bone alkaline phosphatase mass concentration and the determination of bone alkaline phosphatase activity concentration by pre- cipitation with wheat-germ lectin, with respect to within-run imprecision $(n=20)$.

\begin{tabular}{llclc}
\hline Sample & Determination of & Mean & Standard deviation & Coefficient of variation \\
\hline Pooled serum I & mass concentration & $7.8 \mu \mathrm{g} / 1$ & $0.94 \mu \mathrm{g} / \mathrm{l}$ & $12.1 \%$ \\
Pooled serum I & activity concentration & $50.7 \mathrm{U} / 1$ & $1.1 \mathrm{U} / 1$ & $2.2 \%$ \\
Pooled serum II & mass concentration & $22.8 \mu \mathrm{g} / 1$ & $0.81 \mu \mathrm{g} / 1$ & $3.6 \%$ \\
Pooled serum II & activity concentration & $110.5 \mathrm{U} / 1$. & $3.9 \mathrm{U} / 1$ & $3.5 \%$ \\
\hline
\end{tabular}


Tab. 2 Between-day imprecision of the immunoradiometric determination of bone alkaline phosphatase mass concentration $(n=8)$

\begin{tabular}{lllll}
\hline Quality control material & Mean & $\begin{array}{l}\text { Standard } \\
\text { deviation } \\
{[\mu \mathrm{g} / 1]}\end{array}$ & $\begin{array}{l}\text { Coefficient } \\
\text { of variation } \\
{[\%]}\end{array}$ & $\begin{array}{l}\text { Confidence interval } \\
\text { quoted by the manufacturer } \\
{[\mu \mathrm{g} / 1]}\end{array}$ \\
\hline Low control & {$[\mu \mathrm{g} / \mathrm{l}]$} & 2.05 & 10.1 & $17.2-25.0$ \\
High control $^{\mathrm{a}}$ & 20.3 & 2.36 & 2.8 & $70-116$ \\
\hline
\end{tabular}

a Hybritech Inc., San Diego, CA [U.S. A.] (component of Tandem ${ }^{\circledR}-$ Ostase $^{\mathrm{TM}}$; No. 3040 BE; lot No. $3507708 \mathrm{G}$ )

line phosphatase. Varying dilutions $(9+1,8+2, \ldots$, $1+9$ ) were made, employing the zero standard as diluent. Data are shown in figure 1 . The corresponding regression line did not significantly differ from the bisector of the diagram. After correcting the measured concentrations for the dilution factor and expressing them as a percentage of the concentration measured in the undiluted sample, the recovery was found to range from $88 \%$ to $113 \%$ (mean: $103 \%$ ).

\section{Method comparison}

Comparisons between bone alkaline phosphatase mass concentration and activity concentration in reference individuals, as well as in patients receiving renal transplants, are given in figures 2 and 3. From the linear

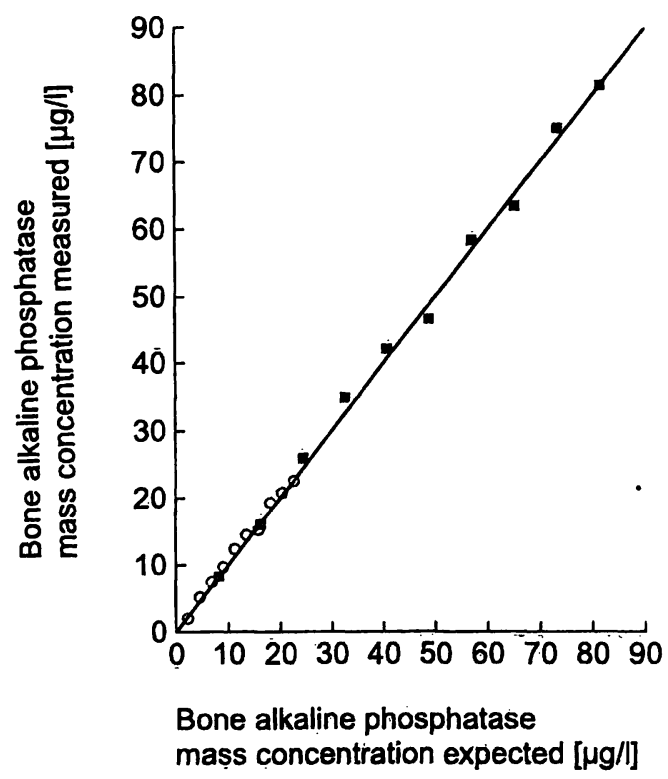

Fig. 1 Linearity of dilution.

Two human sera (designated by squares and circles, respectively) were diluted as described under Results. The line corresponds to the bisector of the diagram. regression equations obtained (see legends to figs. 2 and 3) it can be calculated that a bone alkaline phosphatase activity concentration of $100 \mathrm{U} / \mathrm{l}$ corresponds to a bone alkaline phosphatase mass concentration of $26 \mu \mathrm{g} / \mathrm{l}$.

\section{Reference interval}

In apparently healthy persons bone alkaline phosphatase mass concentration was higher in males than in females $(\mathrm{p}<0.0001)$. The reference intervals $(2.5$ th -97.5 th percentile) are 3.8-21.3 $\mu \mathrm{g} / \mathrm{l}$ (median: $10.2 \mu \mathrm{g} / \mathrm{l}$ ) (males) and 3.4-15.0 $\mu \mathrm{g} / 1$ (median: $6.9 \mu \mathrm{g} / \mathrm{l}$ ) (females) (fig. 4).

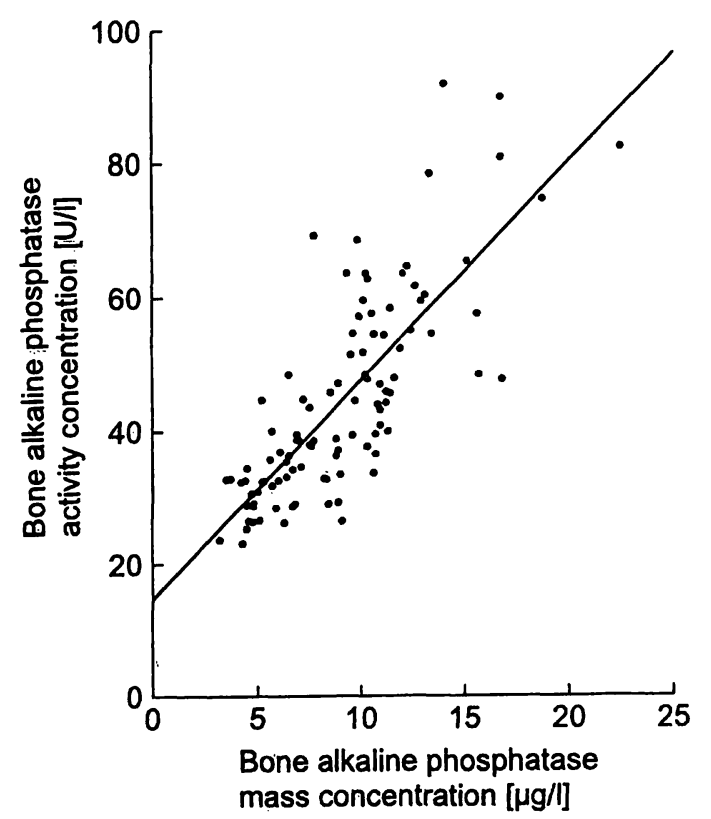

Fig. 2 Comparison of the alkaline phosphatase mass concentration (as determined by an immunoradiometric assay) and the bone alkaline phosphatase activity concentration (as determined by precipitation with wheat-germ lectin) in 102 apparently healthy persons.

The relationship between activity concentration and mass concentration is given by the following regression equation: Bone alkaline phosphatase activity concentration $[\mathrm{U} / \mathrm{H}]=14.81+3.28 \times$ bone alkaline phosphatase mass concentration $[\mu \mathrm{g} / \mathrm{l}](\mathrm{r}=+0.783)$. 
For bone alkaline phosphatase activity concentration the following reference intervals (2.5th-97.5th percentile) were determined: $29-91 \mathrm{U} / \mathrm{l}$ (median: $52 \mathrm{U} / \mathrm{l}$ ) (males) and 23-73 U/l (median: $35 \mathrm{U} / \mathrm{l})$ (females).

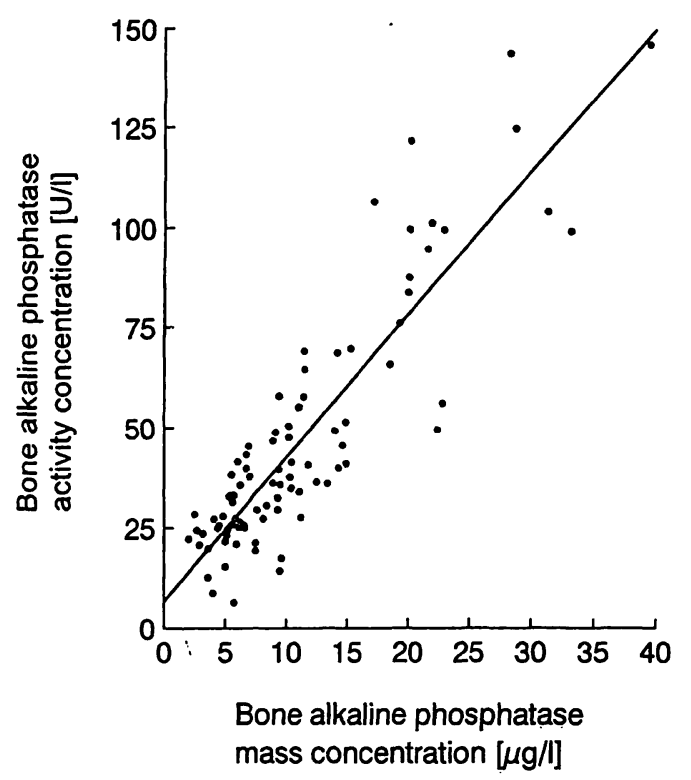

Fig. 3 Comparison of the bone alkaline phosphatase mass concentration (as determined by an immunoradiometric assay) and the bone alkaline phosphatase activity concentration (as determined by precipitation with wheat-germ lectin) in 89 sera from 32 patients receiving renal transplants.

The relationship between activity concentration and mass concentration is given by the following linear regression equation: Bone alkaline phosphatase activity concentration $[\mathrm{U} / 1]=6.77+3.56 \times$ bone alkaline phosphatase mass concentration $[\mu \mathrm{g} / \mathrm{l}](\mathrm{r}=$ $+0.886)$.

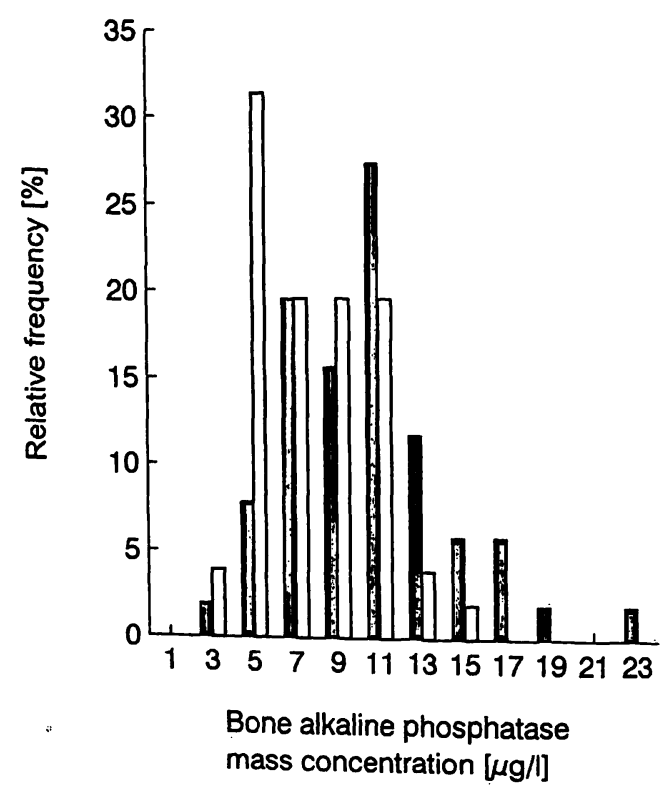

Fig. 4 Distribution of bone alkaline phosphatase mass concentration in apparently healthy persons.

Black bars: males $(n=51)$; white bars: females $(n=51)$.
Interference by non-bone alkaline phosphatase

In 20 sera from patients with hepatobiliary diseases the range of total alkaline phosphatase activity concentration was 217-3270 U/1 (median: $376 \mathrm{U} / 1$ ), and of $L=$ $\gamma$-glutamyl transferase activity : concentration 25-640 $\mathrm{U} / 1$ (median: $120 \mathrm{U} / \mathrm{l}$ ).

The range of bone alkaline phosphatase mass concentration in these patients was $16-206 \mu \mathrm{g} / \mathrm{l}$ (median: 27 $\mu \mathrm{g} / \mathrm{l})$. Out of 20 sera, $18(90 \%)$ showed a bone alkaline phosphatase mass concentration above the upper reference limit $(21.3 \mu \mathrm{g} / \mathrm{l}$ [males] and $15.0 \mu \mathrm{g} / \mathrm{l}$ [females], respectively). The relationship between total alkaline phosphatase activity concentration and bone alkaline phosphatase mass concentration was characterized by a linear correlation coefficient of $r=+0.963$ $(p<0.001)$ (fig. 5).

The range of bone alkaline phosphatase activity concentration was 17-166 U/l (median: $65 \mathrm{U} / \mathrm{l}$ ). Out of 20 sera, $9(45 \%)$ were characterized by a bone alkaline phosphatase activity concentration above the reference limit (91 U/1 [males] and $73 \mathrm{U} / 1$ [females], respectively). There was no correlation between total alkaline phosphatase activity concentration and bone alkaline phosphatase activity concentration $(p>0.1)$.

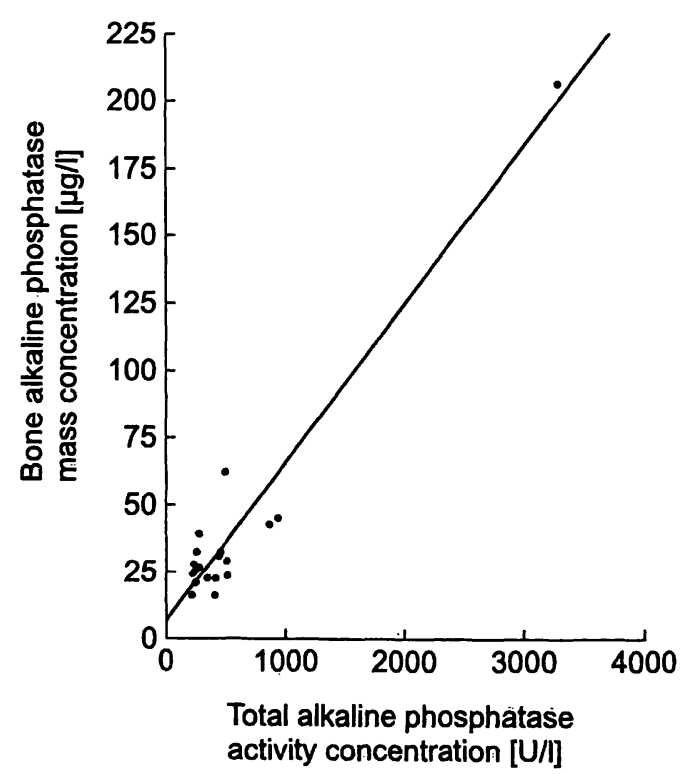

Fig. 5 Relationship between bone alkaline phosphatase mass concentration and total alkaline phosphatase activity concentration in 20 patients with hepatobiliary diseases.

The relationship between the results of the two methods is given by the following linear regression equation: Bone alkaline phosphatase mass concentration $[\mu \mathrm{g} / \mathrm{l}]=6.779+0.059 \times$ total alka line phosphatase activity concentration $[\mathrm{U} / \mathrm{l}] \mathrm{r}=+0.963, \mathrm{p}<$ 0.001 ). 


\section{Discussion}

The immunoradiometric determination of bone alkaline phosphatase is characterized by a linear relationship between the mass concentration of bone alkaline phosphatase and the measuring signal up to $120 \mu \mathrm{g} / \mathrm{l}$.

A drawback of the immunoradiometric assay is its high within-run and between-day imprecision for values within the normal range.

The upper reference limits of bone alkaline phosphatase activity concentration established by us correspond to those reported earlier (5). There is a marked dependence of reference values on sex (5); in adults from 20 to 50 years old this may be explained by an interrelationship between bone alkaline phosphatase values and sex hormones, especially oestrogens (8).

Our results for bone alkaline phosphatase activity concentration (as determined by precipitation with wheatgerm lectin) in patients with hepatobiliary diseases are concordant with those reported by Behr \& Barnert (9), who observed that in more than half of patients with hepatitis of differing origin, as well as in patients with cholestasis, bone alkaline phosphatase activity concentration (as assessed by precipitation with wheat-germ lectin) was increased (up to $725 \mathrm{U} / \mathrm{l}$ ) without accompanying signs of bone affection. In contrast to the liver alkaline phosphatase molecules that occur in serum, those isolated from liver tissue can be precipi-

\section{References}

1. Harris, H. (1989) The human alkaline phosphatases: What we know and what we don't know. Clin. Chim. Acta 186, 133150.

2. Schiwara, H.-W. (1990) Trennung der alkalischen Phosphatase Isoenzyme mit Lektin-Affinitäts-Elektrophorese und LektinFällung. Lab. Med. 14, 466-471.

3. Rosalki, S. \& Ying Foo, A. (1984) Two new methods for separating and quantifying bone and liver alkaline phosphatase isoenzymes in plasma. Clin. Chem. 30, 1182-1186.

4. Bergmeyer, H. U., Büttner, H., Hillmanin, G., Kreutz, F. H., Lang, H., Laue, D., Pilz, W., Rick, W., Schmidt, E., Schmidt, F. W., Stamm, D. \& Szasz, G. (1972) Empfehlungen der Deutschen Gesellschaft für Klinische Chemie. Standardisierung von Methoden zur Bestimmung von Enzymaktivitäten in biologischen Flüssigkeiten. Experimentelle Begründung der optimierten Standard-Bedingungen. Z. Klin. Chem. Klin. Biochem. 10, 182-192.

5. Rosalki, S. B., Ying Foo, A., Burlina, A., Prellwitz, W., Stieber, P., Neumeier, D., Klein, G., Poppe, W. A. \& Bodenmüller, H. (1993) Multicenter Evaluation of Iso-ALP test kit for measurement of bone alkaline phosphatase activity in serum and plasma. Clin. Chem. 39, 648-652.

6. Szasz, G. (1974) $\gamma$-Glutamyl-Transpeptidase, in Methoden der enzymatischen Analyse, 3rd edn. (Bergmeyer, H. U., ed.) pp. 757-762, Verlag Chemie, Weinheim. tated with wheat-germ lectin, presumably because membrane-localized glycosyltransferases modify the enzyme molecules as they pass into the intravasal space (9). As a result of increased liver cell permeability in patients with hepatobiliary diseases, liver alkaline phosphatase is possibly not modified by the membrane-localized glycosyltransferases mentioned above and is therefore precipitated by wheat-germ lectin, resulting in falsely high values for bone alkaline phosphatase activity concentration. Biliary alkaline phosphatase, which is a complex of liver alkaline phosphatase with membrane fragments, is not responsible for implausibly high values of bone alkaline phosphatase activity concentration, because Triton X-100 prevents coprecipitation of this isoform (9).

Falsely high levels of bone alkaline phosphatase mass concentration are possibly due to cross-reactivity of the antibodies employed for the immunoassay of bone alkaline phosphatase with liver alkaline phosphatase (10), so that the diagnostic validity of the test is strongly limited in patients with an increased release of liver alkaline phosphatase into plasma.

Further investigations are required to determine the clinical value of the immunochemical determination of bone alkaline phosphatase mass concentration in serum.

\section{Acknowledgement}

We thank Miss V. Matzeu for skilful technical assistance.

7. Sachs, L. (1988) Statistische Methoden, Planung und Auswertung, 6th edn., Springer, Berlin Heidelberg New York London Paris Tokyo.

8. Schiele, F., Henny, J., Hitz, J., Petitclerc, C., Gueguen, R. \& Siest, G. (1983) Total bone and liver alkaline phosphatase in plasma: Biological variations and reference limits. Clin. Chem. 29, 634-641.

9. Behr, W. \& Barnert, J. (1986) Quantification of bone alkaline phosphatase in serum by precipitation with wheat-germ lectin: A simplified method and its clinical plausibility. Clin. Chem. $32,1960-1966$.

10. Hill, C. S. \& Wolfert, R. L. (1989) The preparation of monoclonal antibodies which react preferentially with human bone alkaline phosphatase and not liver alkaline phosphatase. Clin. Chim. Acta 186, 315-320.

Dr. med. Wolfgang Withold

Institut für Klinișche Chemie und

Laboratoriumsdiagnostik

Medizinische Einrichtungen der

Heinrich-Heine-Universität Düsseldorf

Moorenstraße 5

Postfach 101007

D-40001 Disseldorf

Germany 
